\title{
PÉ DIABÉTICO: CONDUTAS DO ENFERMEIRO
}

\author{
Gardênia Ingrid Leal de Sá Marques Santos Graduanda de Enfermagem pela Escola \\ Bahiana de Medicina e Saúde Pública.
}

\author{
Jéssica Barbosa Mendes Capirunga Graduanda de Enfermagem pela Escola \\ Bahiana de Medicina e Saúde Pública.
}

Olívia Souza Castro Almeida

Enfermeira. Mestre na área do cuidar no desenvolvimento humano. Professora Assistente do curso de Enfermagem da Escola Bahiana de Medicina e Saúde Pública.

Endereço para correspondência: gardeniaingrid@ yahoo.com.br

\begin{abstract}
RESUMO
O pé diabético é responsável pelo grande número de internamentos e morbimortalidade dos portadores de diabetes mellitus. A maioria das úlceras podem receber tratamento ambulatorial, porém, quando associadas a infecção, precisam ser tratadas a nível hospitalar. A avaliação sistemática dos pés é essencial na identificação dos fatores de risco e na redução das chances de ulceração e amputação. O presente estudo possui como objetivo analisar na literatura nacional as informações referentes às condutas do enfermeiro perante ao tratamento $\mathrm{e}$ prevenção dos pacientes acometidos com pé diabético. Este estudo é uma revisão de literatura sistemática. A coleta de artigos foi feita no banco de dados do LILACS (Literatura Latino-Americana e do Caribe em Ciências da Saúde), foram utilizados 22 artigos, que contemplam de forma integral os critérios de inclusão. Os resultados mostraram que existem diversas técnicas de tratamento para o pé diabético e que o papel do enfermeiro é de grande importância no tratamento e prevenção para o pé diabético. Concluiu-se que estes profissionais devem estar sempre capacitados e treinados para prestar uma atenção integral, humanizada e acolhedora.
\end{abstract}

Palavras-chave: Pé diabético; Cuidados de enfermagem; Autocuidado; Terapia; Prevenção e controle.

\section{DIABETIC FOOT: THE NURSE CONDUCTS}

\begin{abstract}
The diabetic foot is responsible for the large number of hospitalizations and morbimortality of patients with diabetes mellitus. Most ulcers can be treated with outpatient therapy; however, when associated with infection, they may require hospital treatment. A systematic evaluation of the feet is essential in identifying the risk factors and reducing the risk of ulceration and amputation. The purpose of the present study is to review the existing national literature concerning the nurse's conduct in the prevention and treatment of patients with diabetic foot . This study is a systematic literature review. The articles were collected from the LILACS (Latin-American and Caribbean Center on Health Sciences) database. 22 articles, which fully meet the inclusion criteria were used . The results showed that there are several techniques for the treatment of the diabetic foot and the role of the nurse is crucial in the treatment and prevention of the diabetic foot. Therefore, it was concluded that these professionals must always be qualified and trained to provide a comprehensive, humane and welcoming approach to patient care.
\end{abstract}

Keywords: Diabetic foot; Nursing care; Self care; Therapy; Prevention \& control. 


\title{
PIE DIABÉTICO: CONDUCTAS DE ENFERMERAS
}

\author{
RESUMEN
}

El pie diabético es responsable del gran número de internaciones y morbimortalidad de los portadores de diabetes mellitus. La mayoría de las úlceras pueden recibir tratamiento ambulatorio, sin embargo, cuando asociadas a infección, necesitan tratamiento a nivel hospitalario. La evaluación sistemática de los pies es esencial en la identificación de los factores de riesgo y en la reducción de las oportunidades de ulceración y amputación. El presente estudio tiene como objeto analizar en la literatura nacional la información respecto a las conductas del enfermero ante al tratamiento y prevención de los pacientes con pie diabético. Este estudio es una revisión de literatura sistemática. La recolección de artículos se hizo en la base de datos del LILACS (Literatura Latinoamericana y del Caribe en Ciencias de la Salud), fueron utilizados 22 artículos, que contemplan en forma íntegra los criterios de inclusión. Los resultados mostraron que existen diversas técnicas de tratamiento para el pie diabético y que el rol del enfermero es de gran importancia en el tratamiento y prevención para el pie diabético. Se concluye que estos profesionales deben estar siempre capacitados y entrenados para prestar una atención total, humanizada y acogedora.

Palabras clave: Pie diabetic;atención de enfermeira; Autocuidado; Terapia; Prevención \& control.

\section{INTRODUÇÃO}

O termo pé diabético pode ser definido como “infecção, ulceração e ou destruição dos tecidos profundos", é geralmente associado à doença vascular periférica e às anormalidades neurológicas em membros inferiores. ${ }^{(1)}$

A Organização Mundial da Saúde (OMS) estimou em 1997, que 20\% a 35\% dos portadores de Diabetes Mellitus (DM) após 15 anos de doença, terão algum grau de neuropatia, e $85 \%$ dos casos evoluem para amputação. No Brasil, a prevalência de ulceração nos pés de diabéticos tipo 2, vai de $5 \%$ a $10 \%$, e $15 \%$ destes, terão algum tipo de lesão nos pés ao longo da vida. ${ }^{(2-4)}$

O pé diabético é responsável pelo grande número de internamentos e morbimortalidade, além do impacto socioeconômico dos portadores de DM. Ocasiona um período de internação mais prolongado e exige cuidados específicos, além de aumentar o número de consultas ambulatoriais. ${ }^{(6)}$

As lesões de pé diabético são consideradas multifatoriais, podendo ser associada ao tipo de Diabetes, tipo 2 mais frequente, ao tempo de evolução da doença, a neuropatia diabética periférica e a doença vascular periférica. ${ }^{(1,5)}$

A neuropatia periférica afeta $50 \%$ dos portadores de DM com mais de 60 anos, acontecendo de três formas: motora, como atrofia e miastenia de pequenos músculos, alterando a estrutura do pé, quantidade de colágeno, queratina e tecido adiposo, modificando os locais de pressão e deformidades ao deambular; autonômica, reduz a sudorese dos pés, contribuindo para surgimento de fissuras e rachaduras, e sensorial, forma mais comum, ocorre 
a perda da sensibilidade, sensação de calor, pressão e propriocepção, em que pequenos ou maiores traumas acontecem com repetição e não são percebidos pelos pacientes. ${ }^{(7)}$

A doença vascular periférica (DVP) é um dos fatores de risco para o pé diabético, caracteriza-se pela redução dos pulsos periféricos, isquemia, atrofia dos membros inferiores e sensação dolorosa nos pés relacionada ao ato de deambular com piora progressiva. A associação de DVP com tabagismo, aterosclerose e dislipidemia deve ser sempre investigada, pois a junção desses fatores acarretam o surgimento precoce das ulcerações e no retardo ou dificuldade de cicatrização das lesões. ${ }^{(8)}$

Os fatores de risco que podem ser associados à úlcera no pé englobam: úlcera ou amputação prévia, neuropatia (por causa da debilitação sensitivo-motora), trauma (andar descalço, calçado inadequado, ferimentos nos pés por objetos perfuro cortantes), biomecânica (engloba diminuição da mobilidade articular, proeminências ósseas que são áreas de risco, deformidade no pé por osteoartropatia, calos, doença vascular periférica, condições socioeconômicas, baixa condição social, inacessibilidade ao sistema de saúde, negligência ao tratamento e falta de prevenção). ${ }^{(1)}$

A avaliação sistemática dos pés é essencial na identificação dos fatores de risco e na redução das chances de ulceração e amputação. Deve ser associada a história clínica do paciente, investigando a ocorrência de lesões ou amputações prévias, observação de incapacidade do paciente para realizar o auto-cuidado com os pés e realização de testes com monofilamento de $10 \mathrm{~g}$ ou diapasão de $128 \mathrm{~Hz}$, investigando a sensação tátil e dolorosa. Como parte da avaliação realiza-se alguns exames complementares, como: coleta de tecido desbridado para cultura bacteriana, exames radiológicos, entre eles, radiografia digital e a convencional, para auxiliar no diagnóstico de osteomielite. ${ }^{(7,2)}$

A Classificação de Wagner é utilizada na estratificação das lesões de pé diabético. Ela consiste em: Grau 0: pé em risco, presença de fissura interdigital; Grau 1: infecção superficial micótica e/ou bacteriana leves; Grau 2: infecção profunda, atingindo tecido celular subcutâneo, tendões e ligamentos, sem osteomielite; Grau 3: Infecção profunda, com abscesso na região média do pé, com tendinite ou sinovite (inflamação de tecido que encobre as articulações) purulentas e osteomielite; Grau 4: infecção e gangrena localizada em dedos, região plantar anterior e calcanhar; Grau 5: infecção e gangrena. ${ }^{(9)}$

O tratamento do pé diabético é feito através da redução de pressão tecidual, controle e prevenção de infecção, correção isquêmica e todos os cuidados necessários com a lesão. 
Também pode ser necessária intervenção cirúrgica, que a depender da lesão, pode ser por meio de desbridamento ou, em último caso, por meio de amputação. ${ }^{(7)}$

Ainda não existe uma uniformização das ações de educação em saúde voltadas para esses pacientes, mas é notório que essas ações devem ter o objetivo de conscientizá-los, alertando sobre os cuidados devidos e gerar um foco maior para aqueles que sejam identificados com risco potencial para o surgimento das ulcerações. Estes, devem possuir um acompanhamento mais criterioso e passar por uma avaliação clínica a cada três meses. ${ }^{(3)}$

Para um paciente diabético, o cuidado com os pés é de máxima importância para evitar lesões. Geralmente, este cuidado é realizado de forma precária e o portador de DM só entende sua importância após o aparecimento das primeiras lesões. Nesse contexto, o enfermeiro deve promover ações educativas para conscientizar essa parcela da população de que é possível prevenir e também sensibilizar esses pacientes quanto aos benefícios desses cuidados específicos com os pés, não esquecendo da continuidade das práticas de prevenção. ${ }^{(10)}$

Esta pesquisa poderá contribuir para o enriquecimento do conteúdo científico sobre o cuidado do enfermeiro acerca do pé diabético, com consequente diminuição de complicações para pacientes acometidos pelo pé diabético, redução de custos desnecessários com o tratamento desses pacientes e as chances de morbimortalidade. É de caráter relevante porque irá fornecer subsídios para intervenções mais eficazes que contribuirão para uma melhoria na qualidade da assistência à saúde desses pacientes.

O presente estudo possui como objetivo analisar na literatura nacional as informações referentes às condutas do enfermeiro perante o tratamento e prevenção dos pacientes acometidos com pé diabético.

\section{METODOLOGIA}

Este é um estudo de revisão de literatura. Contribui para a obtenção de informações atuais sobre o conteúdo em foco, para o conhecimento de estudos já existentes e aspectos abordados por outros autores e, com isso, é possível confrontar as opiniões e aspectos relacionados ao tema. ${ }^{(11)}$

A coleta de artigos foi feita no banco de dados do LILACS (Literatura LatinoAmericana e do Caribe em Ciências da Saúde), tendo como descritores: pé diabético e cuidados de enfermagem; pé diabético e autocuidado; pé diabético e terapia; e pé diabético e prevenção e controle. Os critérios de inclusão foram: trabalhos que abordassem os cuidados com pé diabético com ênfase na assistência de enfermagem, prevenção e controle, publicados 
em português, e texto completo disponível on-line, no formato de artigo científico, composta de trabalhos publicados de 2003 a 2013.

Após a busca, foi realizado leituras flutuantes dos artigos, onde foi possível categorizá-los de acordo com o conteúdo estudado.

\section{RESULTADOS E DISCUSSÃO}

De acordo com a busca realizada, foram encontrados 159 artigos, e somente 22 destes foram contemplados de acordo com os critérios de inclusão. Após seleção e leitura dos artigos caracterizou-se a amostra adquirida em relação ao período de publicação e tipo de metodologia utilizada.

No gráfico 1, é fácil notar que o ano que teve mais publicações foi 2009, com um percentual de 27\%, o que equivale a 6 publicações ao ano. Curiosamente, nos anos de 2013 e 2012, mais recentes, não foram encontrados artigos publicados na base de dados pesquisada com os descritores selecionados, já que é esperado um aumento significativo no número de artigos atuais, se comparado com os anos passados. Nos anos de 2007, 2006 e 2005 houve estabilidade no quantitativo de publicações, todos com $5 \%$ do total de publicações, o que corresponde a somente uma publicação por ano.

Gráfico 1- Percentual de publicação de artigos, de acordo com o ano de publicação, de 2003 a 2013.

\section{Percentual de publicação de artigos, de acordo com 0 ano de publicação}

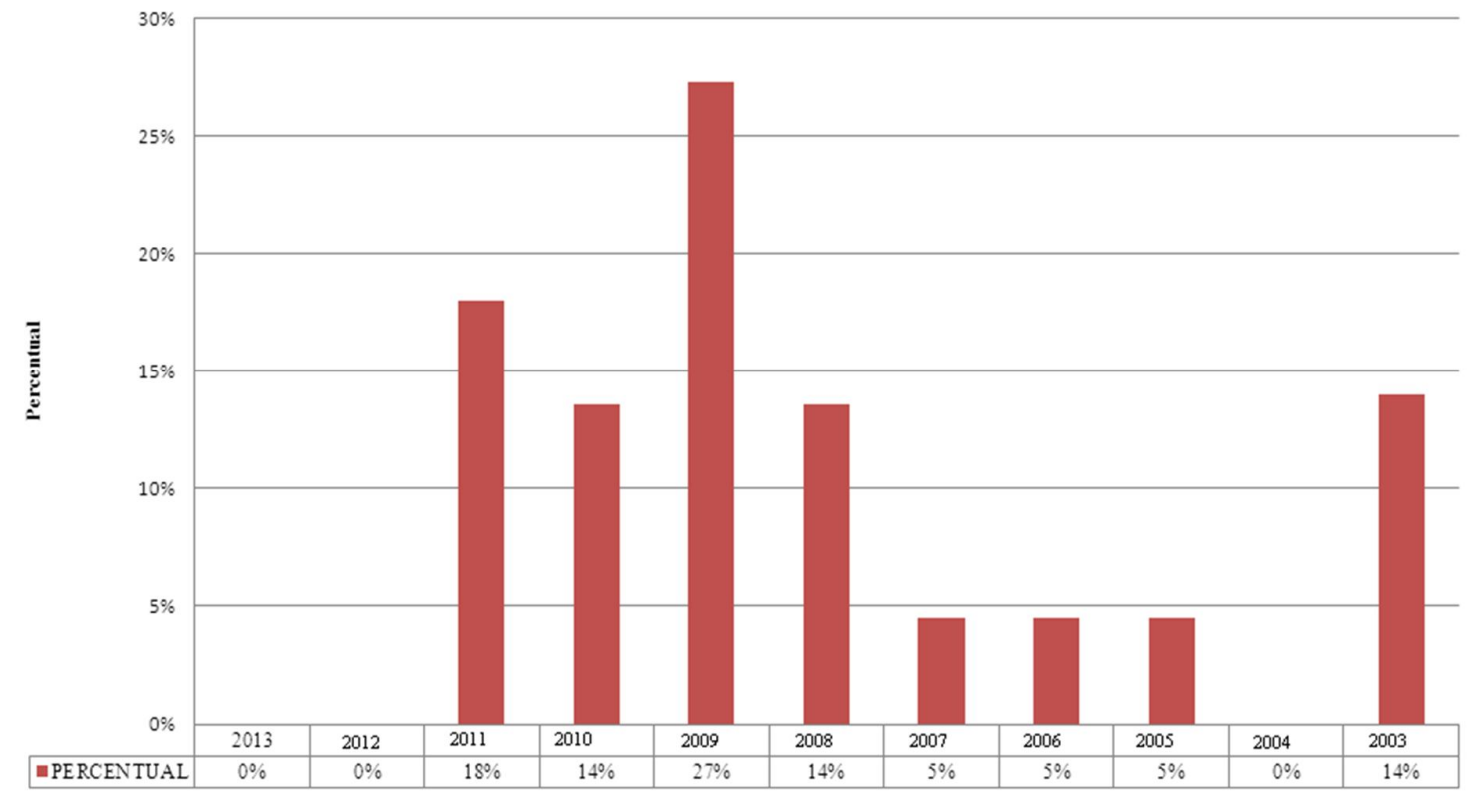


No gráfico 2, pode-se ver que a maioria dos artigos coletados para este estudo são pesquisa de campo, com somente $18 \%$ de revisão bibliográfica.

Gráfico 2- Classificação dos artigos de acordo com a metodologia utilizada

\section{Classificação dos artigos de acordo com a metodologia utilizada \\ - Pesquisa de campo $\quad$ Revisão bibliográfica}

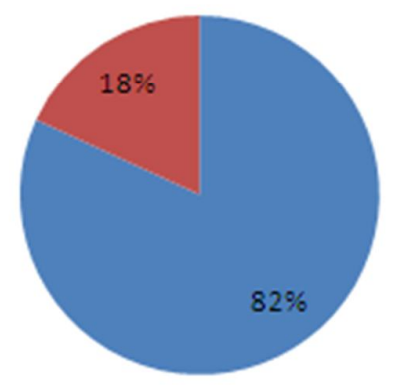

Quanto ao conteúdo, do total de artigos pesquisados, 68\% tratavam sobre a prevenção do pé diabético e $32 \%$ abordavam as questões inerentes ao tratamento desta afecção. Portanto, estes foram divididos em duas categorias: cuidados de enfermagem na prevenção do pé diabético e cuidados de enfermagem no tratamento do pé diabético.

\section{Cuidados de enfermagem na prevenção do pé diabético}

A prevenção do pé diabético é precária e, muitas vezes, ineficaz porque o profissional da saúde, principalmente o enfermeiro, não age da forma correta para prevenir as complicações e educar o paciente. ${ }^{(12)}$ A diretriz da Sociedade Brasileira de Diabetes (SBD), informa que a avaliação dos pés ainda não é uma prática implantada por todos. Uma pesquisa realizada Online pela SBD, mostrou que $65 \%$ dos internautas portadores de DM entrevistados, informaram que nunca tiveram seus pés examinados. Dessa forma, demonstrase que a falta de comprometimento do profissional acaba influenciando na prevenção das lesões. ${ }^{(4)}$

De acordo com Cisneros e Gonçalves, ${ }^{(13)}$ a prevenção do pé diabético é valorizada quando o paciente passa por uma situação de complicação e/ou perda de função de algum segmento do corpo, ou até mesmo quando participa ou compartilha da experiência de outra 
pessoa. Desta forma, é imprescindível que sejam instauradas práticas educativas capazes de modificar esse modo de pensar e a doença não deve ser tratada pelos profissionais como algo ruim, contribuindo assim com a quebra de paradigmas e adesão à prevenção de controle da patologia.

A educação terapêutica deve sensibilizar o paciente para a tomada de novas decisões e medidas de prevenção e pode ser compreendida como medidas que irão capacitar pacientes e familiares no tratamento da patologia já instalada e prevenção de possíveis complicações , por esse motivo, pode ser vista como um fator de proteção para o paciente. ${ }^{(13,21)}$ É necessário atentar que, no caso de pacientes diabéticos, muitos deles utilizam da ajuda de familiares e terceiros para a realização de seus cuidados diários e as práticas educativas devem englobar essas pessoas também. ${ }^{(14)}$

Nos artigos estudados não foram detectadas tecnologias nem mesmo inovações educativas, no contexto das ações educativas que englobem a situação socioeconômica dos pacientes.Contudo, foi observado que quando o enfermeiro ministrava as ações educativas, estas possuíam a mesma didática e metodologia.

É recomendado pelo Consenso Internacional Sobre Pé Diabético, que todos os pacientes deverão ser avaliados pelo menos uma vez ao ano e aqueles que possuem alto risco, devem ser avaliados periodicamente a cada 1 a 6 meses e que as ações de educação terapêutica sejam aplicadas para aqueles pacientes identificados como de alto risco para surgimento das ulcerações, principalmente quando o local possui recursos materiais escassos. ${ }^{1}$

A baixa escolaridade encontrada em alguns estudos ${ }^{(15,18)}$ pode ser uma barreira para as atividades educativas a partir do momento que limita o entendimento das informações transmitidas ao paciente, e o enfermeiro precisa estar atento para esta condição e adaptar suas medidas para que se tornem acessíveis a todos, com a finalidade de contribuir para a mudança de condutas do paciente enfocando o autocuidado e para adesão à prevenção. A educação preventiva contribui para a redução de complicações futuras, principalmente as amputações não-traumáticas ${ }^{(16)}$ e sua eficácia depende diretamente das informações recebidas pelo paciente, da sensibilização capaz de causar mudanças no estilo de vida e desenvolver ações para o autocuidado. ${ }^{(1,19-22)}$

Os principais fatores que contribuem para o autocuidado ineficaz são: a idade avançada (pacientes idosos possuem maior dificuldade de prestar um autocuidado satisfatório), o sexo e o estilo de vida ( crenças, valores e as condições socioeconômicas e de saúde podem influenciar de forma negativa na prestação do autocuidado). Diante desse 
contexto, é papel do enfermeiro acompanhar os pacientes com maior risco de desenvolvimento do pé diabético e orientar quanto ao autocuidado, salientando também a questão do bom controle glicêmico. ${ }^{(15)}$

O controle glicêmico ineficaz, se associado à hipertensão arterial, à obesidade e à dislipidemia é um fator predisponente ao agravamento e/ou surgimento de lesões em pés de diabéticos. Esses fatores são fáceis de mudar com a educação do paciente por meio da adesão deste ao tratamento destas patologias associadas e acompanhamento periódico com o enfermeiro, para prevenir complicações em pés. ${ }^{(12,14,23,24)}$

O enfermeiro tem uma função importante no rastreamento dos pacientes com DM e na prevenção do pé diabético por meio da identificação dos pacientes em risco, de exame clínico que contemple a avaliação física , aferição de pulsos distais e investigação de neuropatia (teste de sensibilidade) e implementações das medidas de prevenção. ${ }^{(17,18)}$ São fatores de risco importantes para o surgimento do pé diabético: idade, tempo de diagnóstico, controle ineficaz da glicemia, tabagismo, hipertensão, obesidade, histórico de úlceras nos pés, outras amputações não-traumáticas (que predispõe à recidiva do pé diabético), educação em saúde deficiente, neuropatia com falta de sensibilidade em pés, baixa acuidade visual, inacessibilidade ao serviço de saúde e cuidados insatisfatórios com os pés (uso do calçado inadequado, andar descalço, uso de escalda-pés, dentre outros). ${ }^{(17,20,21,24)}$

É recomendado que durante a anamnese, a coleta de dados deverá abordar questionamentos diretos relacionados aos sinais e sintomas. Neste momento da avaliação, é necessário que o enfermeiro tenha conhecimento sobre os mecanismos causais das lesões e dos sinais para detecção da evolução de uma infecção. ${ }^{(8)}$

Algumas medidas de prevenção do pé diabético ficam sob responsabilidade da educação em saúde fornecida pelo enfermeiro, tais como o cuidado com a pele e unhas, o uso de sapatos terapêuticos, higiene diária e outros. ${ }^{(25)}$ Portanto, durante a avaliação sistemática do pé do paciente, é recomendado a inspeção criteriosa dos pés com o paciente deitado e em pé, bem como dos calçados e meias. ${ }^{(1)}$

A higiene diária dos pés, seguida da secagem eficaz de toda a extensão do pé e espaços interdigitais é uma medida positiva na prevenção de úlceras. ${ }^{(20)}$ Muitos pacientes possuem o hábito de realizar escalda-pés, porém essa prática favorece o aparecimento de queimaduras que podem evoluir e originar lesões mais graves. O enfermeiro precisa orientar o paciente para que esse hábito seja descontinuado. ${ }^{(16,20)}$ 
O enfermeiro precisa salientar para o paciente a importância do exame dos pés diário e rotineiro. Em um estudo realizado em $2010,{ }^{(12)} 55 \%$ dos pacientes afirmaram que nunca inspecionaram seus pés desde o diagnóstico de diabetes e, dentre os que já realizaram a inspeção dos pés, $52 \%$ afirmam que esta prática foi feita pelo enfermeiro. A verificação diária dos pés, a ser realizada pelo próprio paciente, é um dos cincos pilares dos cuidados adequados para a prevenção do pé diabético e se for realizada rotineiramente, torna-se um fator positivo na prevenção do pé diabético. ${ }^{(14,16,20)}$

A avaliação sistemática deve ser realizada periodicamente pelo enfermeiro, no mínimo uma vez por ano, durante a consulta de enfermagem, com a finalidade de identificar os potenciais problemas presentes nos pés dos pacientes diabéticos. Devem ser avaliadas a sensibilidade protetora plantar (monofilamento de $10 \mathrm{~g}$ ) e a sensibilidade vibratória(diapasão de 128hz), palpação dos pulsos distais e as condições da pele, por meio do exame físico do pé. $^{(1,12,15,17,23,26)} \mathrm{Se}$, ao exame, for constatado que o paciente tem perda da sensibilidade vibratória e tátil pressórica, deve-se suspeitar de neuropatia periférica e o enfermeiro precisa intensificar as medidas de prevenção. ${ }^{(12)}$

As condições dermatológicas devem ser avaliadas, com o objetivo de detectar a presença de calos, umidade nos pés, queratoses, rachaduras, micoses interdigitais e anormalidades das unhas (onicomicoses, onicocriptoses, verrugas, bolhas e úlceras), e assim, instaurar medidas educativas e intervenções para prevenir complicações mais severas. ${ }^{(15,20,26)}$ Os calos aparecem em locais de maior pressão e fricção e estão associados ao uso de calçados inadequados. Portanto, esse é um fator que indica o não seguimento de orientações e uma predisposição ao aparecimento de úlceras. ${ }^{(14)}$

Amaral e Tavarez, ${ }^{(20)}$ constataram que $15,5 \%$ dos entrevistados tinham o hábito de andar descalço, e destes sujeitos, a maioria era do sexo feminino. Nesse tocante, faz-se necessário o uso de calçados adequados para proteger os pés de agentes lesivos à integridade cutânea. $\mathrm{O}$ enfermeiro precisa fazer com que o paciente entenda que pode causar pequenas lesões no pés, aumentando assim o risco de ulcerações. ${ }^{(16)}$ Sapatos apertados e de ponta fina podem lesar a pele do dorso dos dedos e nos lados do antepé, aumentar a pressão sanguínea e causar isquemia local. Já os sapatos folgados, fornecem áreas de atrito com o aparecimento de bolhas e, até mesmo, o favorecimento da entrada de objetos no interior do calçado. ${ }^{(15,20,24)}$

A escolha do calçado geralmente é induzida pela estético do mesmo e as orientações dadas pelo enfermeiro devem contemplar este achado e também devem ser acessíveis financeiramente para o paciente. Se o paciente não tiver condições de comprar um calçado 
terapêutico, já que o custo pode ser elevado, deve-se indicar a este paciente o uso de calçado fechado, tipo esportivo ou mocassim, sem costuras internas.) É necessário também orientar ao paciente que analise a parte interna do sapato antes de calçá-lo, procurando objetos dentro deste que podem causar alguma lesão no pé. ${ }^{(16,20)}$

O calçado terapêutico tem como objetivo reduzir a incidência e recorrência de lesões em pés de pacientes diabéticos, com neuropatia periférica e deve ser utilizado antes de aparecer lesões e deformidades e deve ser individualizado, atentando-se para o estilo de vida do paciente, prática de atividades esportivas e atividade laboral. Dessa forma, o calçado deve ser confeccionado sob medida e respeitar as orientações que constam no Consenso Internacional de Pé Diabético e é papel do enfermeiro orientar o paciente quanto a isso. ${ }^{(12,27)}$ Recomenda-se o uso de calçados comuns de bico largo em casos de calosidades iniciais e pequenas deformidades; em calosidades maiores, dolorosas ou não, é ideal a remoção cirúrgica e o uso de palmilhas e orteses adequadas ao tamanho do pé e que diminuam a pressão plantar. ${ }^{(8)}$

Em estudo por Andrade e colaboradores, ${ }^{(12)}$ somente $19,5 \%$ do total de pacientes pesquisados utilizavam o sapato especial para paciente com diabetes mellitus. O calçado terapêutico reduz o cisalhamento e a pressão e consegue absorver o impacto de traumas.

O enfermeiro deve também orientar o paciente quanto ao uso de meias de algodão, sem elásticos e costura, de cor clara e com o calçado adequado, pois são acolchoadas e conseguem reduzir a pressão, a fricção, o cisalhamento e absorver o suor, evitando assim o aparecimento de micoses interdigitais e onicomicoses. Deve salientar para o paciente a existência de espaço físico no interior do calçado, de modo que o pé não fique apertado e nem que o sapato fique folgado demais. ${ }^{(12,14,16,20)}$

O corte da unhas deve ser realizado após o banho ou, se não for possível, colocar antes os pés em um recipiente com água morna, pois irá favorecer o amolecimento das unhas. A unha deve ser cortada com ângulo reto, sem arredondar os cantos e nem retirar cutículas, ${ }^{(19)}$ já que ao cortar as unhas redondas, poderá ficarum resíduo de unha numa porção mais profunda do dedo, o sulco ungueal distal, que poderá acarretar uma complicação maior. Muitos pacientes diabéticos não têm esse conhecimento e é função do enfermeiro ensinar a maneira correta de lidar com este problema. ${ }^{(14,16,20)}$

Quanto ao uso de hidratantes, um estudo realizado no Ambulatório de Pé Insensível e de Diabetes, em São Paulo, constatou-se que 96,15\% do total de pacientes pesquisados realizavam a secagem correta dos pés após o banho. Neste mesmo estudo, 69,23\% dos 
pacientes hidratavam os pés, prática que deve ser criteriosamente analisada, já que pode favorecer a umidade interdigital e o possível surgimento de infecções. ${ }^{(16)}$

Os cremes hidratantes devem ser utilizados em pernas e pés, com o objetivo de hidratar a pele e evitar o ressecamento, prevenindo lesões. Quanto à isso, é papel do enfermeiro orientar quanto à importância da hidratação da pele, usando uma linguagem fácil e acessível a todos. ${ }^{(20)}$ Estudo realizado realizado por Moreira, Cruz, Valsecchi e Marcon, ${ }^{(14)}$ salienta o uso de cremes hidratantes ou óleos hidratantes com o objetivo de proteger os pés do surgimento de fissuras e rachaduras, fatores predisponentes ao aparecimento de úlceras, já que o paciente com neuropatia diabética pode apresentar ausência ou redução da sudorese na região dos pés. É necessário frisar que o Ministério da Saúde confirma a importância de orientar os pacientes a evitar as áreas interdigitais, pois a umidade gerada pelo hidratante pode ser porta de entrada para o início de uma lesão. ${ }^{(2)}$

$\mathrm{O}$ enfermeiro precisa orientar o paciente quanto à tomada de decisão para a instauração de novos hábitos, com a finalidade de que o paciente incorpore as novas informações recebidas na consulta de enfermagem, quanto à prevenção de lesões. ${ }^{(20)}$

\section{Cuidados de enfermagem no tratamento do pé diabético}

Os processos ulcerativos podem prolongar o período de internação em 59\% a mais do que o esperado, necessitam de um elevado investimento para seu tratamento e tempo prolongado para a reabilitação do paciente. O risco de amputação de membros inferiores em pacientes portadores de diabetes mellitus é 40 vezes maior do que na população geral. ${ }^{(28,29)}$

Alguns sentimentos negativos acometem o paciente portador de pé diabético com ulceração, dentre eles a angústia causada por seu quadro patológico. Nesses casos, em que o paciente demonstra sofrimento psicológico, o enfermeiro deve expressar solicitude ao se mostrar sempre apto para cuidar deste paciente. Nesses casos, o pacientes necessitam de que o profissional se preocupe com ele e dê toda a atenção e respeito inerentes ao processo. ${ }^{(30)}$

O enfermeiro tem atribuições importantes no tratamento do paciente com pé diabético, que deve ser exercido com dedicação, conhecimento e paciência, com o objetivo de minimizar o sofrimento do paciente, orientá-lo corretamente sobre sua patologia e acompanhá-lo no decorrer de seu tratamento. ${ }^{(30,31)}$ Éde grande importância somar as condutas do enfermeiro com a participação dos familiares no cuidado ao paciente com pé diabético, pois a presença e o apoio dos familiares no processo de tratamento proporciona uma maior adesão ao seguimento das orientações, bem como fonte de apoio emocional perante aos 
desafios que podem surgir ao longo do processo, além de ajudar na detecção de sinais e sintomas de agravamento da infecção ou das lesões. ${ }^{(1)}$

O tratamento do pé diabético irá depender do grau de comprometimento do membro. É importante delimitar criteriosamente a etiologia da afecção, pois se houver comprometimento neuropático, o tratamento deve ser com antibióticos e desbridamento, se houver comprometimento vascular, deve ser realizada reperfusão. Nos casos mais graves, pode acontecer a amputação. Também pode-se utilizar curativos industrializados e aplicação local de fatores de crescimento. ${ }^{(31)}$

A amputação geralmente ocorre por causa de disfunções neuropáticas e é precedida de aparecimento de calos e feridas na planta do pé. Este procedimento cirúrgico está indicado nos casos de infecção ou gangrena extensa (quando o membro já não pode mais ser salvo). Os índices de sucesso da amputação são inferiores aos da revascularização. Os diabéticos tabagistas possuem maior chance de amputação, visto que a nicotina promove vasoconstricção, isquemia e gangrena de extremidades, dentre outras complicações. O enfermeiro deve orientar o paciente quanto à importância de comparecer às consultas de enfermagem e quanto à adesão ao tratamento do tabagismo. ${ }^{(31)}$

O enfermeiro se faz importante nos momentos pré e pós operatório à amputação, oferecendo ao paciente apoio psicológico, realizando o controle da glicemia e de curativos. No momento da alta hospitalar, deve orientar o paciente quanto à dieta, aferição da glicemia capilar periodicamente e realização dos curativos em casa. Quando o paciente amputado é idoso, o enfermeiro deve redobrar sua atenção e reforçar as orientações sobre a reabilitação e incentivar o paciente a ser independente e autônomo, dentro de seu contexto social. ${ }^{(31)}$

A escolha da antibioticoterapia usada no tratamento do pé diabético fica à critério médico e precisa levar em consideração a epidemiologia local, outros medicamentos que o paciente já está fazendo uso, as condições clínicas do paciente e estudos clínicos e microbiológicos já existentes. ${ }^{(32)}$ Se houver infecção no pé, é papel do enfermeiro orientar quanto à administração da antibioticoterapia. A hiperglicemia pode ser um sinal de infecção e a febre, leucocitose, calafrios e sinais de inflamação podem estar ausentes de a infecção for recente. A ferida infectada deve ser tratada primordialmente com desbridamento de tecidos mortos, controle da glicemia, curativos e antibioticoterapia. ${ }^{(31)}$

Caiafa, ${ }^{(8)}$ recomenda que devem ser realizados exames de cultura de tecido e osso removidos em procedimentos de desbridamento para evitar a antibioticoterpia empírica, 
promovendo melhor adequação da antibioticoterapia, economizando recursos e consequentemente diminuindo o risco de resistência bacteriana. ${ }^{(8)}$

O processo de desbridamento tem como objetivo remover tecidos mortos, auxiliar no controle da infecção e promover a fase proliferativa da cicatrização. Existem quatro tipos de desbridamento: o cirúrgico, o mecânico ( feito por meio da fricção de gaze embebida em solução fisiológica na ferida ), o autolítico (material industrializado que degrada o tecido morto) e o enzimático (produto industrializado que consegue remover o tecido necrótico sem atingir o tecido saudável). ${ }^{(31)}$

Existem também outros tratamentos para as ulcerações de pé diabético. A oxigenioterapia hiperbárica consiste na inalação de oxigênio concentrado a $100 \%$ e é indicado para lesões graus III e IV. Atua de forma positiva na cicatrização da úlcera promovendo replicação de fibroblastos, síntese de colágeno e neovascularização. O fator de crescimento , pouco utilizado no Brasil, tem como objetivo promover a replicação e síntese da matriz celular da ferida. Também pode ser utilizada a derme humana, obtida por meio da cultura de fibroblastos da pele do prepúcio de recém-nascidos e consegue repor a pele destruída no leito da ferida. ${ }^{(31)}$

Em um estudo realizado por Rezende, Nunes, Melo, Malerbi, Chacra e Ferraz, ${ }^{(29)}$ do total de pacientes internados para tratamento de pé diabético, $15 \%$ foram tratados com curativos e tratamento tópico, $85 \%$ precisaram de intervenção cirúrgica e destes $62,4 \%$ sofreram amputações. O custo estimado para o tratamento dos pacientes deste estudo foi de $\mathrm{R} \$ 4.461,04$ por internação. ${ }^{(29)}$

Um estudo de caso $^{(33)}$ relatou a eficácia do uso de aloe vera e colágeno no tratamento de úlceras em pés de diabéticos e reforça assim o papel do enfermeiro no emprego de novas alternativas para o tratamento desses pacientes.

Outro caso clínico, ${ }^{(34)}$ utilizou fototerapia com luzes LEDs associada à sulfadiazina de prata no tratamento do pé diabético e concluiu que a terapêutica teve eficácia clínica.

Um relato de caso, ${ }^{(35)}$ abordou sobre o uso de curativos com solução de papaína em lesões ulcerativas nos pés, demostrando ser uma técnica eficaz, de baixo custo, fácil manipulação e que ajuda na ativação de tecido de granulação e desbridamento. Portanto, o uso da solução de papaína pode contribuir para a redução dos custos do tratamento, tempo de hospitalização e diminuição da necessidade de intervenção cirúrgica.

Para prestar um cuidado integral ao paciente acometido pelo pé diabético, o enfermeiro deve somar o emprego dos curativos especiais corretos com o desenvolvimento de 
estratégias de educação terapêutica eficazes para esses pacientes e seus familiares, adaptandose às peculiaridades do grupo alvo, junto com o conhecimento sobre o tratamento correto das úlceras de pé diabético. ${ }^{(1)}$

\section{CONSIDERAÇÕES FINAIS}

O cuidado ao paciente com pé diabético deve ser integral e respeitar as características socioeconômicas de cada indivíduo ou grupo, além de suas crenças e conhecimentos. Dessa forma, o enfermeiro deve estar sempre atualizado e capacitado sobre os mais diversos tipos de tratamento e técnicas de educação em saúde para desenvolver um cuidado humanizado, acolhedor e que possua adesão satisfatória dos pacientes.

Com o presente estudo, é perceptível, através do número de publicações no tocante da prevenção do pé diabético, que o enfermeiro é um sujeito norteador das ações educativas. Portanto, a enfermagem precisa se reconhecer enquanto ciência e o enfermeiro entender seu papel de líder e educador, com o objetivo de fomentar o crescimento científico e a atualização dos profissionais.

O tratamento de lesões de pele, em modo geral, é um assunto vasto que conta com a atuação do enfermeiro de forma crescente, principalmente com o crescimento da Enfermagem Baseada em Evidências. O enfermeiro é sujeito plenamente atuante no que diz respeito ao tratamento tópico das lesões de pele, porém, com a busca realizada foram encontrados poucos artigos relatando o papel do enfermeiro no tratamento do pé diabético.

Diante do que foi explicitado, o presente estudo conseguiu cumprir seu objetivo inicial, com a ressalva de que é necessária a realização de outros estudos sobre o tema para que o enfermeirose configure como um profissional em constante atualização, com a meta final de prestar assistência de qualidade para os usuários do sistema de saúde.

\section{REFERÊNCIAS}

1. Grupo de Trabalho Internacional Sobre Pé Diabético. Consenso Internacional sobre Pé Diabético. Brasília: Secretaria de Estado de Saúde do Distrito Federal, 2001.

2. Brasil. Ministério da Saúde. Cadernos da Atenção Básica - Diabetes Mellitus. Cadernos da Atenção Básica n 16. Brasília: Ministério da Saúde 2006:39-42.

3. Rocha RM, Zanetti ML, Santos MA. Comportamento e conhecimento: fundamentos para prevenção do pé diabético. Acta Paul Enferm, 2009;22(1):17-23. 
4. Sociedade Brasileira de Diabetes. Tratamento e acompanhamento do diabetes mellitus diretrizes. Sociedade Brasileira de Diabetes, 2009.

5. Laurindo MC, Recco DC, Roberti DB, Rodrigues CDS. Conhecimento das pessoas diabéticas acerca dos cuidados com o pés. Arq Ciênc Saúde 2005 Abr/Jun;12(2):80-4.

6. Vigo KO, Torquato MTCG, Silvério IAS, Queiroz FA, Guanilo MCDLTU, Pace AE. Caracterização de pessoas com diabetes em unidades de atenção primária e secundária em relação a fatores desencadeantes do pé diabético. ActaPaul Enferm2006;19(3):296-303.

7. Brasileiro JL, Oliveira WTP, Monteiro LB, Chen J, Pinho Jr EL, Molkenthin S, Santos MA. Pé diabético: aspectos clínicos. J Vasc Br 2005;4(1):11-21.

8. Caiafa JS, Castro AA, Fidelis C, Santos VP, Silva ES, Sitrângulo Jr. CJ.. Atenção integral ao portador de pé diabético. J. vasc. bras Porto Alegre 2011;10(4 Suppl 2):1-32.

9. Assumpção EC, Pitta GB, Macedo ACL, Mendonça GB, Albuquerque LCA, Lyra LCB, Timbó RM, Buarque TLL. Comparação dos fatores de risco para amputações maiores e menores em pacientes diabéticos de um Programa de Saúde da Família. J Vasc Bras 2009; $8(2): 133-138$.

10. Fernandes MT, Silva LF. O pé diabético de clientes e seu autocuidado: Enfermagem na educação em saúde. Escola Anna Nery Revista de Enfermagem, Rio de Janeiro, 2005;(9)1: 95-102.

11. Silva EL, Menezes EM. Metodologia da pesquisa e elaboração de dissertação. Florianópolis: UFSC, 2005.

12. Andrade NHS, Sasso-Mendes KD, Faria HTG, Martins TA, Santos MA, Teixeira CRS, Zanetti ML. Pacientes com diabetes mellitus : cuidados e prevenção do pé diabético em atenção primária à saúde. Rev. enferm. UERJ, Rio de Janeiro, 2010 Out/Dez;18(4):616-21.

13. Cisneros LL, Gonçalves, LAO. Educação terapêutica para diabéticos: os cuidados com os pés na realidade de pacientes e familiares. Ciência \& Saúde Coletiva, 2011,16(Supl. 1):15051514.

14. Moreira RC, Cruz CFR, Valsecchi EASS, Marcon SS. Vivências em família das Necessidades de cuidados referentes à insulinoterapia e prevenção do pé diabético. Rev Gaúcha Enferm., Porto Alegre (RS) 2008 Jun;29(2):283-91.

15. Ochoa-Vigo K, Torquato MTCG, Silvério IAS, Queiroz FA, De-La-Torre-Ugarte-Guanilo MC, Pace AE. Caracterização de pessoas com diabetes em unidades de atenção primária e secundária em relação a fatores desencadeantes do pé diabético. Acta Paul Enferm 2006;19(3):296-303.

16. Martin VT, Rodrigues CDS, Cesarino CB. Conhecimento do paciente com diabetes mellitus sobre o cuidado com os pés. Rev. enferm. UERJ, 2011;19(4):621-5. 
17. Santos ICRV, Bezerra GC, Souza CL, Pereira LC. Pé diabético: apresentação clínica e relação com o atendimento na atenção básica. Rev Rene, Fortaleza, 2011 Abr/Jun;12(2):393400.

18. Santos ICRV, Nunes ENS, Melo CA, Farias DG. . Amputações por pé diabético e fatores sociais: implicações para cuidados preventivos de enfermagem. Rev Rene, Fortaleza, 2011 Out/Dez;12(4):684-91.

19. Carvalho RDP, Carvalho CDP, Martins DA. . Aplicação dos cuidados com os pés entre portadores de diabetes mellitus. Cogitare Enferm 2010;15(1):106-9.

20. Amaral AS, Tavares DMS. Cuidados com os pés: conhecimento entre pessoas com diabetes mellitus.Rev. Eletr. Enf., 2009;11(4):801-10.

21. Cosson ICO, Ney-Oliveira F, Adan LF. Avaliação do conhecimento de medidas preventivas do pé diabético em pacientes de Rio Branco, Acre. Arq Bras Endocrinol Metab, 2005;49(4):548-56.

22. Coelho MS, Silva DMGV, Padilha MIS. Representações sociais do pé diabético para pessoas com diabetes mellitus tipo 2. Rev. esc. enferm. USP 2009 Mar;43(1):65-71.

23. Schmid H, Neumann C, Brugnara L. O diabetes melito e a desnervação dos membros inferiores: a visão do diabetólogo. J Vasc Br 2003;2(1):37-48.

24. Ochoa-Vigo K, Pace AE. Pé diabético: estratégias para prevenção. Acta Paul Enferm 2005;18(1):100-9.

25. Batista F, Pinzur M, Monteiro A, Taira R. Educação em pé diabético. Einstein., 2009; 7(1):24-7.

26. Bortoletto MSS, Haddad MCL, Karino ME. Pé diabético, uma avaliação sistematizada. Arq. Ciênc. Saúde Unipar, Umuarama, 2009;13(1):37-43.

27. Cisneros LL. Avaliação de um programa para prevenção de úlceras neuropáticas em portadores de diabetes. . Rev Bras Fisioter, 2010;14(1);31-7.

28. Martins CF, Thofehrn MB, Amestoy SC, Lange C. O fazer que faz a diferença: cuidando da pessoa acometida por ferida - pé diabético. Cienc Cuid Saude 2007;6(Suplem. 2):448-453.

29. Rezende KF, Nunes MAP, Melo NH, Malerbi D, Chacra AR, Ferraz MB. Internações por pé diabético: comparação entre o custo direto estimado e o desembolso do SUS. Arq Bras Endrocrinol Metab, 2008;52(3):523-30.

30. Moreira RC, Sales CA. O cuidado autêntico ao ser com pé diabético sob o enfoque heideggeriano. Cienc Cuid Saude 2009 Out/Dez;8(4):515-522.

31. Hirota CMO, Haddad MCL, Guariente MHDM. Pé diabético: o papel do enfermeiro no contexto das inovações terapêuticas. Cienc Cuid Saude 2008 Jan/Mar;7(1):114-120. 
32. Sader HS, Durazzo A. Terapia antimicrobiana nas infecções do pé diabético. J Vasc Br, 2003;2(1):61-66.

33. Oliveira SHS, Soares MJGO, Rocha PS. Uso de cobertura com colágeno e aloe vera no tratamento de ferida isquêmica: estudo de caso. Rev Esc Enferm USP,2010;44(2):346-51.

34. Minatel DG, França SC, Enwemeka CS, Frade MAC. Fototerapia (LEDs 660/890nm) no tratamento de úlceras de perna em pacientes diabéticos: estudo de caso. An Bras Dermatol. 2009;84(3):279-83.

35. Carvalho FIC, Silva JPN, Bittencourt MC, Junior LCB. Uso de papaina no tratamento de lesões ulcerativas de pacientes portadores de Pé diabético: relato de cinco casos. Revista Paraense de Medicina 2010 Abr/Jun; 24(2):65-70. 